\title{
Panel Discussion
}

\section{Palliative Care and Hospice}

Moderater:

Hasan Shanawani, MD

Assistant Professor

Wayne State University School of Medicine

Detroit, Michigan

\section{Panelists:}

Frederick A. Smith, MD, FACP

Long Island Jewish Medical Center (LIJMC)

Lake Success, New York

North Shore University Hospital

Manhasset, New York

Tanveer Mir, MD, MACP

Associate Chief, Geriatrics and Palliative Medicine

Long Island Jewish Medical Center

North Shore Long Island Jewish Health System

New York, New York

Mary Lahaj, MA,

Clinical Pastoral Education (CPE) Certified

Chaplain, Groton School

Groton, Massachusetts
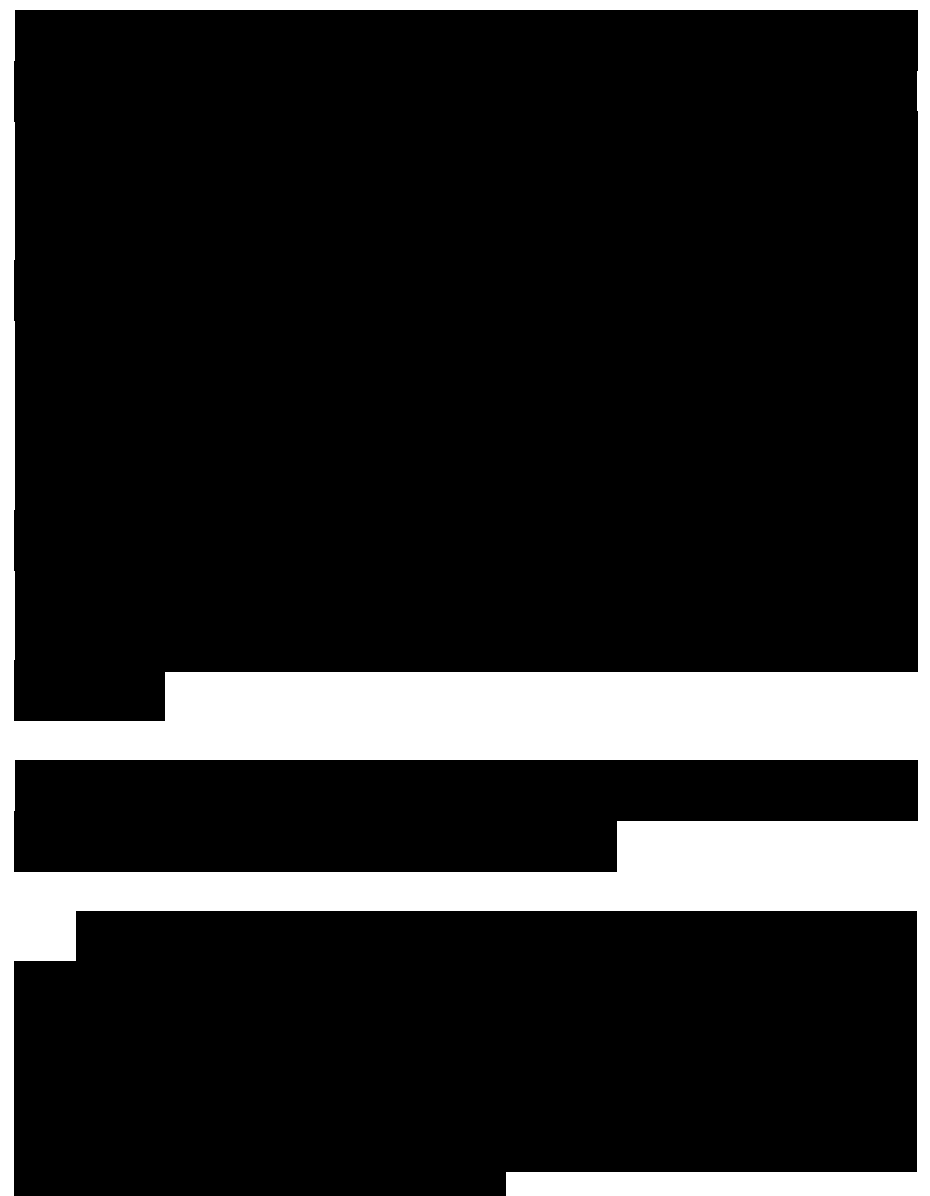


\section{Discussion}

Article DOI: http://dx.doi.org/10.5915/43-3-9462

Video DOI: http://dx.doi.org/10.5915/43-3-9462V

Aasim Padela, MD: Thank you so much for your presentation. I think it highlights the problem many of us in this room face whether we are physicians, Muslim chaplains, imams, or scholars. Dr. Shanawani and I wrote about the problem of us being labeled the "Islamic bioethics experts" because we are part of a minority community. You highlighted that the roles of a chaplain are different than those of the imam.

As a community we need to delineate the core competencies of these different professionals. We need to disseminate this knowledge, as Muslim chaplaincies are gaining popularity. You mentioned a case where a Shia Muslim refused to allow the withdrawal of life support from his dying cousin. I am from Michigan, where there are many Shia Muslims. I have worked at a hospital there, interviewing physicians, staff, and patients about this issue.
Many of the Shia families in this community did not want to withdraw care. During discussions, the family members would say, "We cannot allow removal of the ventilator; you are going to make us kill him." The families are going think we are killing their loved one or we are hastening his death. Because of this, the hospital and its physicians came up with the idea to assume the role of limited paternalism. The policy is that when a person is near the end of life and physicians think there is no benefit to continue efforts, they would withdraw care without asking the family. Some people might find this difficult to accept based on the principle of autonomy and negating the role of the family. Physicians justify this because there is a greater burden in having the family discussion of deciding who is the proxy. They would ask the patient or the family: "Do you trust me as your physician? Do you want me to do what is best for the patient? If I do not think there is any benefit, is it alright for me to make the decision?" I think that in Western context, the four principles of medical bioethics break down. What are your thoughts on that? 
Hasan Shanawani, MD: Chaplain Lahaj, just because some identify themselves as Muslims does not mean they walk with an Islam 101 textbook under their arm. I think of you as being an ambassador of facilitating pastoral care, based on your experience. Is that unique to the Muslim community? I think you have substantially more training than the average hospital clinical pastor. What have you observed with other faith traditions? As intensivists, we get a little persnickety when people say "withdrawal of care." I withdraw life support all the time, but I do not stop my continuing care. I would like to think that after I pull the ventilator I am still caring for the patient.

Chaplain Lahaj's response: I think because Muslims are the "new kids on the block," the expectation is that the Muslim chaplain and every Muslim will know everything about their religion. For example, Harvard Medical School and Brigham and Women medical students who are Muslims are inundated with questions about the Muslim patient, about Islam, and they, frankly, are not interested in becoming this ambassador if they are working or are going to school. They just want to get on with their life and their work. They ask me to give a presentation on cultural competency on the Muslim patient, and, of course, I am the expert on that. The Muslim chaplain being on the staff of a secular institution is beneficial because there are Muslims in many different stations of life. There are Muslims who may have feelings of guilt and have spent their life without going to a mosque and without having an imam or wanting to see an iman. There are young Muslim couples who are not married and are expecting a child, and they do not want to see an imam. Part of our training in chaplaincy is not to judge people about how they grieve, how they live, or how they die -- none of it. I think that being affiliated with a secular institution makes people feel safe. They still need God, and they still want their newborn babies blessed. They feel safe in a secular environment and believe that an iman will judge them. Not all imams are judgmental, but, nonetheless, they do represent that tradition.

Question from the Audience: As a chaplain, I have often found a conflict with the goals of patient autonomy and the desire to lessen suffering. I know some Christian patients believe suffering is beneficial; it is the way Jesus died, and they feel that this is a way of repenting. I deal with this the best I can. I explain that God would like them to be repentant but to be peaceful as well. The question is how would Muslims feel about this? There is also the situation when family members keep shopping for a doctor until they get the opinion they want to hear or until they get a doctor who will do the surgery because all the other surgeons refused, realizing it was futile. I saw this in a few cases, and not necessarily with Muslim patients. There was a family that kept taking a patient from place to place, and the man got weaker and weaker. It was so pitiful, and yet when you try to speak with the patient, the family often will not let you get close to the patient alone. The patient says I want to do what my family needs me to do. They feel they are helping their families. Is that a conflict that might happen with Muslim families as well, and how might you deal with that?

Chaplain Lahaj's response: We are all in that boat together. I found Muslim patients are very grateful to doctors for the efforts they have showed them and for their interest in their religion and culture. There are cases where there is a conflict between the doctor and the family. I also know that what applies to people of other faiths would apply to Muslims, too. I was on call for a case involving an Orthodox Jewish doctor, who was totally committed to saving a patient's life. As I was the only chaplain in the 900bed facility, the family and the head nurse called me to the floor. The patient, who was completely in her right mind, had asked to be taken off the respirator and oxygen. She had her health proxy in place, her six adult children were there, and her requests were witnessed by the health proxy, by the head nurse and by the doctor. Everyone agreed with her wish except the doctor who said, "No way. Your mother is walking out of here." The family was thrown into hysteria, anger, and sadness. They did not know what to do with this conflict, so they called me. I did not know what to say to the doctor. I just suggested that it would be helpful to bring in the palliative care team doctor. The attending doctor said, "I know the team, I will call them." The team was open to a discussion about death and dying, and finally the doctor said, "I am going to hand my patient over to "Dr. Soand-So' on the palliative care team." Everyone was happy.

Hasan Shanawani, MD: I would like to direct this question to you and to the other chaplain who asked the question. Both of you brought up the concept of religion, and you talk about how you are providing 
pastoral care to patients outside of your own faith tradition, which I think is one of the more important elements of pastoral care. You are not providing care to a particular religion, you are there to make sure that certain needs are met that do not fall necessarily within other aspects of patient care. Could you both comment on this? Dr. Mir, you brought it up in your talk as well, how do you bring religion into your clinical practice, and Chaplain Lahaj, how do you minister or provide pastoral care services to someone when it is clear that the two of you do not share the same faith tradition? What are your professional obligations?

Dr. Mir's response: One of the domains of assessment in palliative care and hospice is spiritual care. When we talk to the patient or the families, we weave it in the question "Are you religious?" because religion is a drop-down menu for all patients when admitted. Sometimes it is more than that. We have had patients who could come from any religious background. If the patient is Jewish, I ask if they would like to speak to a rabbi, and they will say, "Absolutely not, I am not observant. I have not been to the temple in 25 years." I then ask the patient if they would like to speak to a social worker or a chaplain about life issues. This would be of value because we have a lot of decisions to make, and the patient will need some emotional support. I would say that 9 out of 10 people do accept nondenominational spiritual care if they have not been to their place of worship or if they do not belong to a church group or a temple group or any other community-based religious affiliation. At the end of life, people are open to that because they need those resources.

I would like to mention a good resource for everyone, that is a web site called ethnomed.org, a University of Washington web site. It talks about cultural competence and what we need to do to understand different patients. The web site features different ethnic religious groups, the refusal of care, the acceptance of care, and the differences between the role of a translator and an interpreter. A translator is someone who actually translates the language. An interpreter is someone who has some understanding of the culture, ethnic, and religious background and may be able to interpret those things in the face of critical life and death decisions. I think some of us play the role of interpreters as well. Although we are physicians and chaplains, we are who we are by cre- dentialing. I think beyond our credentialing, the unspoken word is that as humanitarians we can all provide support to all patients across denominations and try to identify the issues. That is the approach we use.

Chaplain Lahaj's response: I agree. That is standard procedure. I was trained as an interfaith, or multifaith, chaplain. I do not think the world is ready to have a Muslim on the hospital staff as the interfaith chaplain, but I was trained to do that. Chaplains are assigned to floors and areas, and when we go to see a patient, we do not just start talking "God-talk." Instead, we make a spiritual assessment. I think the most difficult thing for me is to determine how to minister to someone of another faith at a critical time, how to give meaning to a celebration or a calamity. An example of this was a celebration of a newborn when I was on call and asked to bless a Catholic baby. I went to the room, and there was the mother, the aunt, the grandmother, and the baby. I was prepared with a quote from Jesus (AS) that I was comfortable using as part of the spontaneous prayer. Then we came to the part where they needed to do the sign of the cross. This is where I have to draw the line for my own participation. So what was I going to do? Well, alhamdulillah, I looked at the grandmother - who had a big cross hanging from her neck - and I asked her if she would like to participate in the ceremony and to do the sign of the cross. She was happy to do it. We all just burst into tears, it was just such a wonderful moment, alhamdulillah.

Dr. Safdar Chadda: I congratulate Chaplain Lahaj for being the first woman Muslim chaplain I have encountered. My question is what kind of training did you have, and why you chose to be a Muslim chaplain? My second part of the question is to Dr. Mir. I had a hospice experience myself two years ago. My wife was in hospice care, and I encountered the most wonderful people I have ever met. I have seen their service and compassion, their courtesy, and all kind of help they provide. However, as the speaker pointed out, there is a reluctance and fear associated with hospice. There is a general fear that once you are in hospice, you are doomed. Is there anything we can do about the impression people have?

Chaplain Lahaj's response: I was advised to become a chaplain by two imams who had hospital duty. They said a female chaplain was needed in this hospital because women do not want to see the men. A chaplain has to study different religions and have 
a higher degree from a seminary. Once that prerequisite is met and the candidate is accepted into a program, it is pretty much a Christian program. However, the Jews modified it, and now they are modifying it for the Muslims. They ask you which ecclesiastical organization is standing up for you. I asked if God was okay for an ecclesiastical organization. Most people take one unit of clinical pastoral education, which is a kind of education that takes place in a hospital. Then they go from the hospital and work in a prison venue, in the military, or on a college campus. Most people, especially Christian clergy, are required to take at least one unit of clinical pastoral education. The maximum is four, and usually people take one and they say, "I did it." I had four units, and I am still standing. The road to professional chaplaincy now requires one to have 2,000 hours of work in the field after the training, so it is a long journey.

Dr. Mir's response: When we see patients for palliative consults or for advanced illnesses, we do not bring up the word "terminal." We always use the words "advanced illness." It is softer, it is easier on the families, and they can use the term. We tell them hospice care is not only a support for them, but also a means of service. We tell them that hospice is a sixmonth benefit. If they do well, they can be discharged. It is a myth that everyone dies in hospice. It is a good support system for the patient, family, and all the loved ones. Overall, as a result of all these efforts, I think you will be seeing an upstreaming of hospice. No one would think that a palliative care consultant would be called into a trauma room, but that is what we do in our day-to-day practice. One member of our team is there on any given day at one of the larger trauma centers, talking to the family about withdrawal of care or about what the goals of care are at the time. I would not say it is a withdrawal of care, but rather withdrawal of a ventilator or whatever other life support measures are in place. Clearly, there is a change in mindset, and there is lot of education going on. The talk about the "death panels" last year did not help anyone. Having the support of hospice at the end of life is one of the most important things. It reduces suffering, it supports the family, it supports the patients. Calling it a death panel did a disservice to what we have.

We do need the support of the media. If we had television shows such as $E R$ focusing on hospice at the end-of-life situations, it would be great. Cardiopulmonary resuscitation (CPR) on television shows that show have an extremely high success rate, according to an article in the New England Journal of Medicine. Not one show portrays that the patient ends up dying or something bad happens to him. Clearly, we need to change the mindset that CPR is always successful. In fact, only $30 \%$ of the patients who survived CPR may be still alive at the end of one year. Therefore, we need to change the body of public information. The last point that I want to make is that there is a lot of research being done on hospice, and that would change outcomes. We saw the first article in the New England Journal of Medicine. I think there will be more articles to come.

\section{Editor's Notes}

a. Diem SJ, Lantos JD, Tulsky JA. Cardiopulmonary resuscitation on television - miracles and misinformation; N Engl J Med. 1996;334:1578-82. http://dx.doi.org/10.1056/NEJM199606133342406 